\title{
Efeito hipolipidêmico do suco de camu-camu em ratos
}

\author{
Hypolipidemic effect of camu-camu \\ juice in rats
}

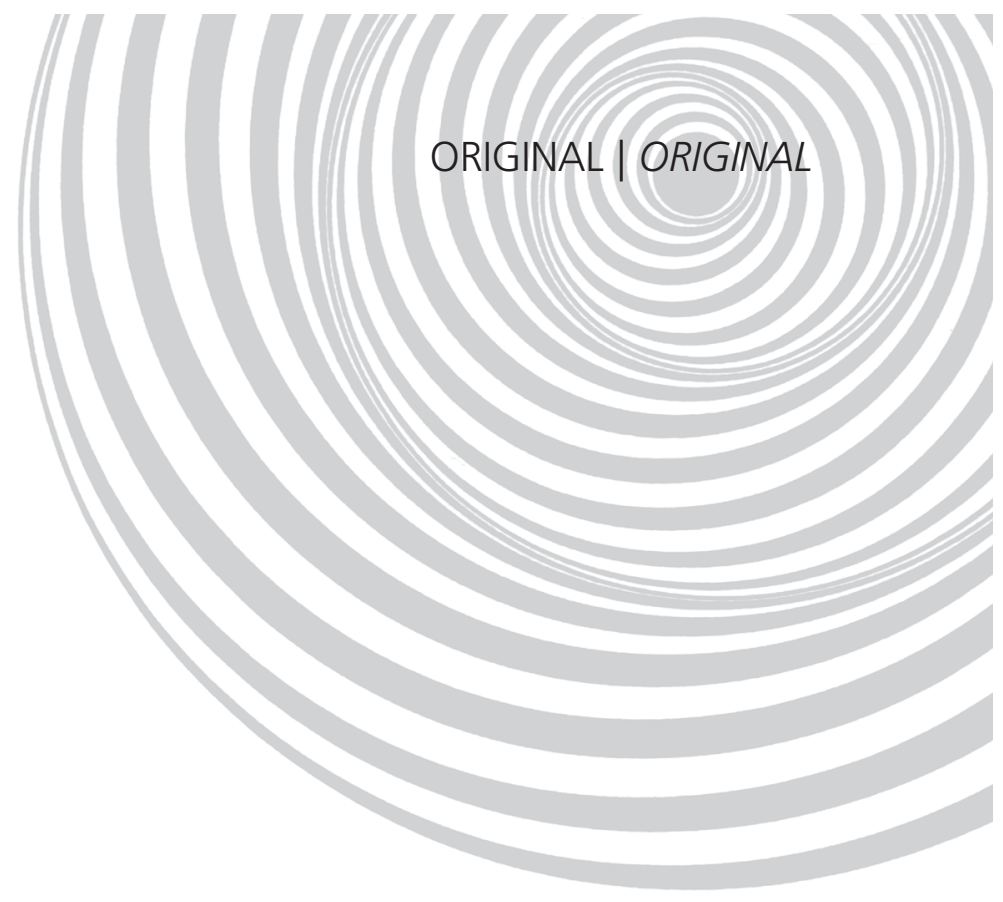

Maíra Cássia SCHWERTZ

Jeniffer Resende Patrocínio MAIA ${ }^{1}$

Risonilce Fernandes Silva de SOUSA²

Jaime Paiva Lopes AGUIAR²

Lucia Kiyoko Ozaki YUYAMA²

Emerson Silva LIMA'

RE S U M O

\section{Objetivo}

Este estudo teve como objetivo avaliar o potencial hipolipidêmico do suco de camu-camu (Myrciaria dubia (Kunth) McVaugh) em ratos dislipidêmicos.

\section{Métodos}

Foram utilizados 72 ratos (Rattus norvegicus var. albinus) machos adultos da linhagem Wistar, com peso médio de $200 \mathrm{~g}$. O experimento foi dividido em duas fases: indução da dislipidemia e tratamento. Para indução da dislipidemia, todos os ratos receberam ração hiperlipídica (ração comercial adicionada a 10,0\% de banha suína, 1,0\% colesterol e 0,1\% de ácido cólico) durante 21 dias. Na fase de tratamento, 40 ratos dislipidêmicos foram divididos aleatoriamente em 5 grupos $(n=8)$, sendo 3 deles submetidos a tratamento com diferentes concentrações de suco de camu-camu $\left(0,4 \mathrm{~mL} . \mathrm{kg}^{-1}, 4,0 \mathrm{~mL} . \mathrm{kg}^{-1}\right.$ e $\left.10 \mathrm{~mL} . \mathrm{kg}^{-1}\right)$ por 14 dias, 1 grupo submetido a tratamento com quercetina $\left(10 \mathrm{~mL} . \mathrm{kg}^{-1}\right)$ e 1 grupo hiperlidêmico. Estes dois últimos foram mantidos como parâmetro, ao lado do grupo basal. Para avaliar o efeito modulador do suco de camu-camu no perfil lipídico dos ratos, foram verificadas as concentrações de triacilgliceróis, colesterol total, lipoproteína de alta intensidade e lipoproteína de baixa intensidade, no plasma, assim como os níveis de colesterol fecal e hepático. Também foram observados o controle da ingestão de ração e a avaliação da massa corporal.

\section{Resultados}

As diferentes doses de suco de camu-camu e de quercetina apresentaram efeitos moduladores do perfil lipídico, ou seja, redução de triacilgliceróis, colesterol total, excreção fecal de colesterol, bem como redução do colesterol hepático. Salienta-se que os melhores resultados foram obtidos com a concentração de $10 \mathrm{~mL} . \mathrm{kg}^{-1}$. Em relação

1 Universidade Federal do Amazonas, Faculdade de Ciências Farmacêuticas. Manaus, AM, Brasil.

2 Instituto Nacional de Pesquisas da Amazônia, Coordenação de Sociedade, Ambiente e Saúde. Av. André Araújo, 2936, Aleixo, 69060-001, Manaus, AM, Brasil. Correspondência para/Correspondence to: LKO YUYAMA. E-mail: <yuyama@inpa.gov.br>. 
36 | MC SCHWERTZ et al.

à massa corporal, os ratos que receberam essa concentração de suco de camu e quercetina mantiveram peso significativamente inferior ao obervado nos demais tratamentos, tanto no início quanto ao final da intervenção. Resultado similar foi observado quanto ao consumo de ração.

\section{Conclusão}

O suco de camu-camu apresentou efeito modulador do perfil lipídico em ratos dislipidêmicos. Os resultados poderão ser utilizados como referência em futuros trabalhos acerca desse fruto amazônico.

Termos de indexação: Dislipidemias. Quercetina. Ratos.

\section{A B S T R A C T}

\section{Objective}

This study evaluated the potential hypolipidemic effect of camu-camu juice (Myrciaria dubia (Kunth) McVaugh) in dyslipidemic rats.

\section{Methods}

Seventy-two adult male Wistar rats (Rattus norvegicus var. albinus Berkenhout) with an average weight of $200 \mathrm{~g}$ were used. The experiment was divided into two phases: induction of dyslipidemia and treatment. Dyslipidemia was induced by a high-fat diet (commercial feed plus 10.0\% lard, 1.0\% cholesterol and 0.1\% cholic acid) given to the animals for 21 days. In the treatment phase, 40 dyslipidemic rats were randomly divided into five groups $(n=8)$. Of these, three were subjected to different treatments with camu-camu juice: $0.4 \mathrm{~mL} . \mathrm{kg}^{-1}, 4.0 \mathrm{~mL} . \mathrm{kg}^{-1}$ and $10 \mathrm{~mL} . \mathrm{kg}^{-1}$ for 14 days. The other two groups were kept as parameters: a basal group (normolipidemic) and a hyperlipidemic group receiving $10 \mathrm{~mL} . \mathrm{kg}^{-1}$ of quercetin (standard treatment). The potential hypolipidemic effect of camu-camu juice was assessed by the following measurements: plasma lipoproteins (triacylglycerol, total cholesterol, high density lipoprotein-cholesterol and low density lipoproteincholesterol), fecal and liver cholesterol, and measurements of feed intake and body weight.

\section{Results}

All dosages of camu-camu juice were hypolipidemic, reducing triacylglycerol, total cholesterol, fecal cholesterol excretion and hepatic cholesterol. The best results were obtained by the $10 \mathrm{~mL} . \mathrm{kg}^{-1}$ dosage of camu-camu juice. Rat body weight and food intake did not vary significantly during the treatment.

\section{Conclusion}

Camu-camu juice has a hypolipidemic effect in dyslipidemic rats. These results can be used as reference for future studies on this Amazonian fruit.

Indexing terms: Dyslipidemia. Quercetin. Rats.

\section{N T R O D U ÇÃ O}

A dislipidemia é uma doença decorrente da alteração do metabolismo lipídico, caracterizada pela elevação dos níveis plasmáticos de Colesterol Total (CT), Lipoproteína de Baixa Intensidade (LDL) e Triglicerídeos (TG), assim como pela redução das concentrações plasmáticas da Lipoproteína de Alta Intensidade (HDL). Essas alterações podem ou não estar associadas ${ }^{1}$. O controle da dislipidemia pode ser atingido por meio de cuidados dietéticos associados a mudanças no estilo de vida, sendo em alguns casos também necessário o tratamento farmacológico. No entan- to, a alimentação é reconhecida como a intervenção mais importante na prevenção e tratamento da dislipidemia².

O consumo de alimentos com altos teores de colesterol e gorduras, principalmente a saturada, associado à baixa ingestão de substâncias antioxidantes e fibras, predispõe à elevação das taxas de colesterol sérico e suas frações e, consequentemente, ao aumento do risco de Doenças Cardiovasculares (DCV) ${ }^{3}$. De outro lado, evidências recentes têm demonstrado que dietas com alto consumo de frutas, hortaliças e grãos podem prevenir inúmeras doenças, benefício este associado à ingestão de substâncias antioxidantes ${ }^{4}$. 
O camu-camu é um fruto amazônico que vem despertando grande interesse devido a seu teor nutricional ${ }^{5}$. Recentemente, ganhou notoriedade por sua elevada concentração de ácido ascórbico ${ }^{6}$ e, além disso, também é fonte de minerais e flavonoides, como a quercetina ${ }^{7,8}$.

Os polifenóis apresentam uma estrutura química comum, derivada do benzeno, ligada a um grupo hidrofílico. Com base em sua estrutura e na maneira pela qual os anéis polifenólicos ligam-se uns aos outros, eles são classificados em quatro famílias: flavonoides, ácidos fenólicos, lignanas e estilbenos. Entre as principais classes de flavonoides incluem-se os flavonóis, as flavonas, as flavanonas, os flavanóis (ou catequinas), as antocianidinas e as isoflavonas ${ }^{9}$. Dentro dos subgrupos dos flavonóis, a quercetina é o flavonoide que mais frequentemente ocorre nos alimentos ${ }^{10}$, sendo principalmente encontrada em frutas cítricas, a exemplo do camu-camu.

Os polifenóis têm recebido muita atenção da comunidade científica por seus numerosos efeitos biológicos e funcionais, como a modulação do perfil lipídico e a sua função antiaterosclerótica, anti-inflamatória, antialérgica, antitumoral, anti-hepatóxica, antiulcerogênica, antimicrobiana, antiviral e vasodilatadora ${ }^{11-14}$.

Pelo fato de o camu-camu ser um fruto com grande potencial terapêutico no controle da dislipidemia e na prevenção de doenças cardiovasculares, estudos experimentais com ratos possibilitam verificar, de forma segura, a eficácia desse fruto no controle e prevenção de doenças relacionadas à dislipidemia. Dessa forma, o presente estudo avaliou o potencial modulador do suco de camu-camu no perfil lipídico de ratos hiperlipidêmicos, o que proporcionou uma ampliação do conhecimento sobre esse fruto amazônico.

\section{M É T O D O S}

\section{Obtenção do suco de camu-camu}

Foram utilizados frutos de camu-camu maduros, procedentes de uma plantação experi- mental em terra firme da Fazenda Yurican, localizada no km 100 da rodovia AM 010, do município de Rio Preto da Eva, Amazonas. Os frutos foram encaminhados ao Laboratório de Alimentos e Nutrição do Instituto Nacional de Pesquisas da Amazônia (INPA), onde foram submetidos a processo de seleção, lavagem em água corrente e potável, sanitização com hipoclorito na proporção de 200ppm por 30 minutos, e enxágue em água corrente e potável. Posteriormente, os frutos foram processados em despolpadeira previamente higienizada, para obtenção do suco. Este foi armazenado em sacos plásticos de $1 \mathrm{~kg}$, devidamente etiquetados e congelados à temperatura de $-15^{\circ} \mathrm{C}$, por 90 dias.

\section{Composição nutricional}

Amostras representativas do suco de camu-camu foram retiradas aleatoriamente para análise da composição nutricional. As análises foram realizadas em triplicata, no Laboratório de Alimentos e Nutrição do INPA. Foram determinadas as concentrações de umidade, proteínas e lipídeos do camu-camu, de acordo com a Association of Official Analytical Chemists $(A O A C)^{15}$. Em relação à composição química da ração comercial, foi considerado o que consta na rotulagem do produto. O percentual de carboidratos foi obtido pela diferença da soma dos demais componentes por 100. As análises dos teores de minerais, como cálcio, potássio, magnésio, ferro, zinco, manganês e cobre, foram realizadas segundo o Instituto Adolfo Lutz ${ }^{16}$. A fibra alimentar foi quantificada segundo Asp et al. ${ }^{17}$; a quercetina, segundo Lees \& Francis ${ }^{18}$; e o ácido ascórbico, por titulação com 2,6-diclorofenolindofenol, segundo Ranganna ${ }^{19}$.

\section{Ensaio biológico}

A metodologia adota foi protocolada sob o $n^{\circ}$ 003147/2010 e aprovada pelo Comitê de Bioética em Experimentação Animal da Universidade Federal do Amazonas. Foram utilizados 
ratos machos, adultos, da linhagem Wistar (Rattus norvegicus var. albinus Berkenhout), com 90 dias de vida, pesando aproximadamente $200 \mathrm{~g}$, provenientes do Biotério Central do INPA, local onde foi realizado o ensaio biológico. Os procedimentos adotados observaram a Lei $n^{\circ} 11.794$, de 2008, para utilização de ratos com fins científicos.

O ensaio biológico foi dividido em duas fases: indução da dislipidemia e tratamento.

Para a indução da dislipidemia foram utilizados 72 ratos. Estes receberam ração hiperlipídica e água ad libitum por 21 dias. A ração hiperlipídica foi preparada com banha suína (adquirida no mercado local), colesterol (C7529, SigmaAldrich ${ }^{\circledR}$, Alemanha) e ácido cólico (C1129, SigmaAldrich ${ }^{\oplus}$, Alemanha), adicionados à ração comercial Labina nas proporções de 10,0\%, 1,0\% e $0,1 \%$, respectivamente. A ração comercial, contendo 4,0\% de lipídeo, 23,0\% de proteína e 5,0\% de fibra, foi triturada e adicionada de banha, colesterol e ácido cólico. Após, foi homogeneizada, peneirada (ABNT TYLER 20, abertura da malha $0,84 \mathrm{~mm}$ ) e acondicionada em saco plástico, à temperatura de $4^{\circ} \mathrm{C}$, até o momento do início do experimento.

Para o tratamento, foram selecionados 40 ratos dislipidêmicos, distribuídos aleatoriamente em 5 grupos: G1 (recebeu apenas ração hiperlipídica); G2 (recebeu ração hiperlipídica + $0,4 \mathrm{~mL} . \mathrm{kg}^{-1}$ de suco de camu-camu); G3 (recebeu ração hiperlipídica $+4,0 \mathrm{~mL} \cdot \mathrm{kg}^{-1}$ de suco de camu-camu); G4 (recebeu ração hiperlipídica + 10,0 $\mathrm{mL} \mathrm{kg}^{-1}$ de suco de camu-camu); G5 (recebeu ração hiperlipídica $+10,0 \mathrm{~mL} \mathrm{~kg}^{-1}$ de quercetina). A quercetina foi diluída em $2 \mathrm{~mL}$ de água destilada, de forma a contemplar a mesma quantidade presente no camu-camu. Os grupos G2, G3, G4, G5 receberam seus respectivos tratamentos via gavage, por 14 dias. O grupo G1 não recebeu nenhum tratamento, mas foi mantido como parâmetro para a dislipidemia. O grupo G5 foi considerado o tratamento padrão. Concomitantemente, os ratos continuaram recebendo água ad libitum. Paralelamente a todo período experimental, foi mantido um grupo basal, que recebeu alimentação normolipídica (ração comercial Labina e água ad libitum) e foi utilizado como padrão de normalidade dos níveis lipídicos (grupo normolipídico).

\section{Avaliação dos tratamentos}

A avaliação das concentrações das lipoproteínas plasmáticas foi realizada semanalmente e individualmente, por meio de amostras de plasma. O plasma foi obtido de amostras de $1 \mathrm{~mL}$ de sangue, coletadas via punção cardíaca, guardadas em tubos de $5 \mathrm{~mL}$ contendo heparina lítica, e centrifugadas a $2.500 \mathrm{rpm}$ por 15 minutos. No dia anterior à coleta, os ratos foram deixados em jejum de 12 horas. Para coleta de sangue, eles foram previamente anestesiados com Cetamim ${ }^{\circledR}$ $(0,15 \mathrm{~mL} / 100 \mathrm{~g}$ de massa corporal) combinado ao analgésico Rompun ${ }^{\circledR}(0,015 \mathrm{~mL} / 100 \mathrm{~g}$ de massa corporal). Nas análises bioquímicas foram utilizados conjuntos de diagnósticos com princípios metodológicos enzimáticos da empresa Labtest Diagnóstica ${ }^{\circledR}$ S.A. (Minas Gerais, Brasil), seguindo o respectivo protocolo. A leitura foi realizada em equipamento automatizado Cobas Mira Plus (Roche ${ }^{\circledR}$, Alemanha). A concentração de LDL foi obtida por meio do cálculo da fórmula de Friedewald.

A concentração de colesterol fecal foi verificada semanalmente por grupo. Amostras de fezes foram coletadas diariamente com o auxílio de bandejas revestidas com jornais, dispostas abaixo das gaiolas. As análises da excreção de colesterol fecal e colesterol hepático foram realizadas segundo Mazzali et al. ${ }^{20}$. Para a obtenção do colesterol hepático, o fígado foi retirado no último dia do tratamento, após a eutanásia dos ratos, com anestésico e analgésico.

O controle do consumo alimentar foi realizado diariamente e para cada animal, por meio da subtração da sobra e desperdício em relação ao peso total da ração oferecida. A aferição da massa corporal foi realizada semanalmente e individualmente para avaliação do ganho ou perda de peso. 
Foram utilizados a análise de variância e o teste de Tukey para a comparação de médias entre os grupos, com um nível de significância de 5\%.

\section{RESULTADOSE DISCUSSÃO}

\section{Composição nutricional do suco de camu-camu}

As concentrações de minerais encontradas no suco de camu-camu (Tabela 1) diferem das concentrações obtidas por Yuyama et al. ${ }^{7}$, os quais analisaram amostras de frutos provenientes das margens do Rio Uatumã. Entretanto, os diferentes tipos de cultivo, terra firme e regiões alagadas ou de várzea podem alterar as características nutricionais do fruto, pois diferenças no solo acarretam alterações morfológicas nos espécimes, o que possivelmente justificaria as diferentes concentrações minerais nos frutos ${ }^{21}$.

De outro lado, Justi et al.22, analisando frutos de camu-camu provenientes de uma plantação experimental de terra firme no Estado Paraná, obtiveram resultados semelhantes aos observados no presente trabalho. Os dados obtidos também corroboram o exposto por Teixeira et al. ${ }^{21}$.

Tabela 1. Concentração de macronutrientes, micronutrientes, umidade e quercetina em $100 \mathrm{~mL}$ de suco de camu-camu.

\begin{tabular}{lc}
\hline Nutrientes & Concentração \\
\hline Carboidrato (g) & 5,33 \\
Lipídeos (g) & 0,60 \\
Proteína (g) & 0,16 \\
Fibras totais (g) & 1,23 \\
Fibras solúveis (g) & 0,48 \\
Fibras insolúveis (g) & 0,75 \\
Vitamina C (mg) & 1686,00 \\
Cálcio $(\mathrm{mg})$ & 7,18 \\
Potássio $(\mathrm{mg})$ & 14,27 \\
Magnésio $(\mathrm{Mg})$ & 0,40 \\
Sódio $(\mathrm{mg})$ & 1,96 \\
Zinco $(\mu \mathrm{g})$ & 0,52 \\
Cobre $(\mu \mathrm{g})$ & 0,19 \\
Ferro $(\mu \mathrm{g})$ & 0,27 \\
Manganês $(\mu \mathrm{g})$ & 0,59 \\
Quercetina $(\mathrm{mg})$ & 400,00 \\
\hline
\end{tabular}

Apesar de o suco de camu-camu conter minerais, suas concentrações são pouco expressivas para ser considerado uma boa fonte de minerais. Mas ele pode ser incluído ao planejamento alimentar, de forma a contribuir para que a ingestão recomendada seja atingida.

As concentrações de macronutrientes, vitamina $\mathrm{C}$ e fibra alimentar (Tabela 2 ) são comparáveis às referidas em diversos trabalhos da literatura ${ }^{22,23}$. O camu-camu é uma excelente fonte de vitamina $C$, característica pela qual ganhou notoriedade ${ }^{6}$. As concentrações médias de vitamina $C$ no suco de camu-camu variam de 845 a $2994 \mathrm{mg} / 100 \mathrm{~g}$, superando as concentrações da acerola ${ }^{24}$; em alguns trabalhos, foram observadas concentrações ainda mais elevadas, de 3571 a $6112 \mathrm{mg} / 100 \mathrm{~g}$ de fruto ${ }^{6,23}$.

A baixa concentração de carboidratos e lipídeos caracteriza o suco de camu-camu como um alimento de baixa densidade energética, o que o torna uma boa opção alimentar para pessoas com restrições energéticas.

A quercetina também foi encontrada em grandes concentrações no suco de camu-camu. A quercetina é o flavonoide mais abundante na dieta humana, representando aproximadamente $95 \%$ do total de flavonoides ingeridos. Suas principais fontes são a cebola (28,4 a 48,6mg/ $100 \mathrm{~g})$, a maçã $(2,1$ a $7,1 \mathrm{mg} / 100 \mathrm{~g})$ e o brócolis $(3 \mathrm{mg} / 100 \mathrm{~g})^{25}$. Maeda et al. ${ }^{23}$, verificando o teor de flavonoides totais presentes no camu-camu (epicarpo e mesocarpo), encontraram aproximadamente $183,3 \mathrm{mg} / 100 \mathrm{~g}$ de fruto, que foram expressos em quantidades de quercetina, valor bem inferior ao observado no presente trabalho. As melhores fontes alimentares de flavonoides são cacau, café, chá preto, vinho e cerveja (aproximadamente $420 \mathrm{mg} / \mathrm{dia}$ ), seguidos de frutas (290mg/ $(\mathrm{dia})^{26}$. No entanto, não existe uma recomendação para ingestão diária de flavonoides, mas apenas uma estimativa de consumo médio, entre $26 \mathrm{mg}$ e $1 \mathrm{~g} / \mathrm{dia}$, para que eles possam trazer benefícios à saúde ${ }^{4}$. Dessa forma, a alta concentração de quercetina presente no suco de camu-camu revela ser ele uma boa fonte alimentar de flavonoides. 
40 | MC SCHWERTZ et al.

Tabela 2. Concentrações das lipoproteínas plasmáticas (mg/dL), em ratos, durante a fase de tratamento.

\begin{tabular}{|c|c|c|c|c|c|c|c|c|}
\hline \multirow{2}{*}{ Grupos } & \multicolumn{2}{|c|}{ Triacilgliceróis (mg/dL) } & \multicolumn{2}{|c|}{ Colesterol total (mg/dL) } & \multicolumn{2}{|c|}{$\mathrm{HDL}(\mathrm{mg} / \mathrm{dL})$} & \multicolumn{2}{|c|}{$\mathrm{LDL}(\mathrm{mg} / \mathrm{dL})$} \\
\hline & Inicial & Final & Inicial & Final & Inicial & Final & Inicial & Final \\
\hline \multicolumn{9}{|l|}{ Basal } \\
\hline Média & $175,6^{\mathrm{a}}$ & $108,4^{b}$ & $76,6^{c}$ & $88,9^{c}$ & $52,5^{a}$ & $50,4^{\mathrm{a}}$ & $18,2^{b}$ & $16,8^{c}$ \\
\hline Desvio-Padrão & 53,1 & 40,7 & 8,4 & 3,7 & 10,2 & 8,4 & 10,6 & 9,0 \\
\hline \multicolumn{9}{|l|}{ G1 } \\
\hline Média & $162,9^{\mathrm{a}}$ & $189,1^{\text {ab }}$ & $181,0^{\mathrm{a}}$ & $200,5^{a}$ & $63,5^{a}$ & $53,5^{\mathrm{a}}$ & $84,9^{a}$ & $109,2^{a}$ \\
\hline Desvio-Padrão & 35,4 & 69,6 & 36,4 & 67,2 & 8,2 & 6,8 & 40,3 & 59,8 \\
\hline \multicolumn{9}{|l|}{ G2 } \\
\hline Média & $179,5^{\mathrm{a}}$ & $72,2^{\mathbf{b c}}$ & $179,0^{\mathrm{a}}$ & $141,2^{\mathbf{b c}}$ & $56,4^{\mathrm{a}}$ & $52,5^{\mathrm{a}}$ & $86,7^{\mathrm{a}}$ & $74,3^{\mathrm{ab}}$ \\
\hline Desvio-Padrão & 38,4 & 21,1 & 31,1 & 33,2 & 8,6 & 9,0 & 44,1 & 34,4 \\
\hline \multicolumn{9}{|l|}{ G3 } \\
\hline Média & $166,4^{\mathrm{a}}$ & $56,1^{b c}$ & $178,9^{\mathrm{a}}$ & $147,4^{\mathrm{ab}}$ & $56,1^{\mathrm{a}}$ & $52,1^{\mathrm{a}}$ & $89,6^{a}$ & $84,0^{\mathrm{ab}}$ \\
\hline Desvio-Padrão & 45,0 & 30,7 & 29,0 & 27,9 & 8,6 & 8,5 & 29,7 & 28,2 \\
\hline \multicolumn{9}{|l|}{ G4 } \\
\hline Média & $152,0^{a}$ & $26,4^{c}$ & $126,2^{\mathbf{b}}$ & $113,5^{b c}$ & $50,1^{a}$ & $39,6^{a}$ & $45,7^{b}$ & $68,6^{\mathrm{abc}}$ \\
\hline Desvio-Padrão & 40,9 & 16,0 & 30,4 & 22,6 & 9,0 & 10,9 & 34,8 & 27,7 \\
\hline \multicolumn{9}{|l|}{ G5 } \\
\hline Média & $174,5^{a}$ & $25,0^{c}$ & $127,8^{\mathbf{b}}$ & $91,2^{c}$ & $56,9^{a}$ & $44,0^{\mathrm{a}}$ & $36,1^{\mathrm{b}}$ & $42,2^{b c}$ \\
\hline Desvio-Padrão & 25,3 & 11,1 & 26,8 & 17,5 & 11,5 & 11,9 & 28,1 & 23,7 \\
\hline
\end{tabular}

Grupo basal: ratos que receberam ração comercial; G1: ratos que receberam ração hiperlipídica; G2: ratos que receberam ração hiperlipídica e 0,1 $\mathrm{mL}$ de suco de camu-camu; G3: ratos que receberam ração hiperlipídica e $1 \mathrm{~mL}$ de suco de camu-camu; G4: ratos que receberam ração hiperlipídica e $2 \mathrm{~mL}$ de suco de camu-camu; G5: ratos que receberam ração hiperlipídica e $2 \mathrm{mg}$ de quercetina. As médias são seguidas de desviopadrão. Letras diferentes no sentido vertical indicam diferença significativa em nível de 5\% de probabilidade, pelo Teste de Tukey.

\section{Avaliação dos tratamentos}

Após 21 dias de indução da dislipidemia, as lipoproteínas plasmáticas, colesterol e LDL do grupo de ratos que receberam ração hiperlipídica (G1), aumentaram significativamente em relação ao grupo basal, o que demonstra que o método de indução foi eficaz (Tabela 2).

Os ratos que receberam $10{\mathrm{~mL} . \mathrm{kg}^{-1}}^{-1}$ de suco de camu-camu apresentaram redução significativa das taxas de triacilgliceróis, tanto quanto o grupo que recebeu quercetina, adotado como tratamento padrão (Tabela 2).

Embora existam lacunas a serem preenchidas sobre a atividade biológica dos compostos bioativos e consequentemente sua biodisponibilidade, um dos mecanismos de ação dos flavonoides no metabolismo de lipídeos, em particular triacilgliceróis, parece envolver a inibição da enzi- ma tiroxina 5'-desiodinase, responsável pela desiodinação da tiroxina, hormônio da tireoide T4, em triodotironina, hormônio da tireoide T3. A ação dos hormônios tireoideanos resulta da ligação com receptores específicos no núcleo. A afinidade dos receptores nucleares para o Triodotironina (T3) é 10 vezes maior do que para a Tiroxina (T4). Essa atividade é extremamente importante, pois a síntese aumentada do hormônio da tireoide poderia acarretar efeitos anabolizantes, distúrbios cardiovasculares e aumento no volume da mitocôndria, provocando maior oxidação nos sistemas enzimáticos e menor produção de ATP (Adenosina trifosfato), devido à ocorrência do desacoplamento das fosforilações ${ }^{27}$.

A maior redução de colesterol total e LDL-c $(p<0,05)$ foi constatada nos ratos que receberam $10 \mathrm{~mL} \mathrm{~kg}^{-1}$ de suco de camu-camu (G4) e de quercetina (G5) (Tabela 2). O mecanismo atribuído aos flavonoides, para justificar a redução das 
concentrações de CT e LDL-C, pode ser provavelmente o aumento da excreção de sais biliares nas fezes e o aumento da atividade do sistema mitocondrial hepático, com o consequente aumento do metabolismo lipídico ${ }^{28}$. Kirk et al..$^{13}$ sugeriram que a redução do colesterol total decorre do aumento da atividade dos receptores de LDL nos hepatócitos, responsáveis pelo aumento da endocitose e pela redução dos níveis plasmáticos de colesterol total.

Em relação às concentrações de HDL-c, não se observou diferença significativa entre os tratamentos, independentemente do tipo de intervenção. A concentração de HDL-c pode estar relacionada ao metabolismo de triglicerídeos. Após a lipólise dos quilomícrons e Lipoproteínas de Muito Baixa Densidade (VLDL) pela lipase lipoproteica, os fosfolipídios e apolipoproteínas são captados pelas HDL-C, que modificam sua densidade de $\mathrm{HDL}_{3}$ para $\mathrm{HDL}_{2}$, tornando a concentração de triglicerídeos inversamente proporcional à concentração de HDL-c ${ }^{29,30}$, fato não constatado no modelo utilizado.

Dentre todos os tratamentos, os ratos que receberam $10 \mathrm{~mL} . \mathrm{kg}^{-1}$ de suco de camu-camu foram os que apresentaram maior efeito modulador do perfil lipídico, tanto quanto a quercetina. A diferença entre os dois tratamentos é que a quercetina administrada aos ratos do G5 é purificada e o camu-camu não. Vários outros constituintes não identificados no presente estudo podem estar presentes no suco de camu-camu, sendo objeto de estudos em curso, com métodos mais aprimorados.

A quercetina mostra uma profunda interação com a albumina, provavelmente por sua habilidade em assumir uma conformação planar. Em pH fisiológico, muitos polifenóis interagem com a cabeça polar de fosfolipídios na superfície da membrana, via formação de pontes de hidrogênio. Um grande número de grupos hidroxil na estrutura dos polifenóis, bem como um aumento no $\mathrm{pH}$, podem levar à desprotonação de grupos hidroxil, aumentando as interações entre os polifenóis e as superfícies da membrana. Essa adsorção de polifenóis provavelmente limita o acesso de oxidantes aquosos à superfície da membrana e o seu ataque inicial a essa superfície ${ }^{31}$. Muitos estudos mostram que os polifenóis possuem a capacidade de proteger a LDL da oxidação, assim como de reduzir a tendência do sangue a formar coágulos, manter os níveis de pressão sanguínea e elevar a capacidade antioxidante ${ }^{32}$. 0 reflexo da atividade antioxidante dos polifenóis sugere que seu metabolismo apresente um efeito considerável. Por exemplo, a hidrofobicidade dos polifenóis é intermediária entre a vitamina C, altamente hidrofílica, e a vitamina $\mathrm{E}$, altamente hidrofóbica. Os polifenóis agem nas interfases hidro-lipídicas e podem estar envolvidos nas vias de regeneração das vitaminas $C$ e $E^{24}$. Tem sido relatado o efeito sinérgico da quercetina com a vitamina $C$, potencializando a ação antioxidante desse flavonoide no organismo ${ }^{32}$.

Foi verificado um aumento significativo da excreção de colesterol fecal em todos os grupos de ratos que receberam suco de camu-camu, sendo que $\mathrm{G} 2$ apresentou maior excreção que os demais, seguido do grupo G5 (Tabela 3). A possível explicação para esse resultado é a ação dos flavonoides sobre a inibição da lipase pancreática, que impede a absorção de lipídeos em nível intestinal, acarretando maior excreção de gordura nas fezes ${ }^{33}$.

Os níveis de colesterol hepático mostraram-se mais elevados entre os grupos tratados com suco menos concentrado, observando-se maior redução desses níveis no grupo G4 - inferior, porém, à observada em G5 (grupo quercetina). Os flavonoides aumentam o metabolismo mitocondrial hepático, favorecendo a excreção de colesterol do fígado, pela formação de sais biliares ${ }^{28}$.

Os resultados demonstraram ainda que não foram encontradas alterações na massa corporal dos ratos tratados com a concentração de $10 \mathrm{~mL} . \mathrm{kg}^{-1}$ de suco de camu-camu, em relação aos animais tratados com a mesma concentração de quercetina. Esses achados corroboram os dados obtidos por Rodrigues et al. ${ }^{4}$, que não encon- 
traram alterações na massa corporal dos ratos tratados com o flavonoide rutina.

O consumo alimentar dos ratos que receberam a concentração de $10 \mathrm{~mL} \cdot \mathrm{kg}^{-1}$ de suco de camu-camu ou de quercetina, ao final do experimento, não diferiu no nível de $p<0,05$. De outro lado, esse consumo foi significativamente inferior ao observado no grupo hiperlipídico e nos grupos tratados com outras concentrações de camu-camu (Tabela 4), divergindo dos resultados obtidos por Rodrigues et al. ${ }^{4}$ Tais resultados sugerem que o efeito dos flavonoides sobre os parâmetros bioquímicos não está relacionado a mudanças na eficiência alimentar, nem ao ganho de peso.

\section{O N C L US Ã O}

A ingestão do suco de camu-camu apresentou efeito modulador do perfil lipídico em ratos. Dentre as doses de suco utilizadas, a 10 $\mathrm{mL} . \mathrm{kg}^{-1}$ foi a que apresentou melhor resposta sobre o perfil lipídico dos ratos, reduzindo o CT e o LDL-c. Essa dose pode ser estabelecida como referência para futuros trabalhos experimentais ou para extrapolação em seres humanos. Os resultados obtidos neste trabalho são promissores quanto à futura utilização do suco de camu-camu no controle e prevenção de doenças associadas à dislipidemia.

Tabela 3. Concentração média de colesterol hepático $(\mathrm{mg} / \mathrm{dL})$ e fecal dos ratos durante o tratamento.

\begin{tabular}{|c|c|c|c|c|c|}
\hline \multirow{3}{*}{ Grupos } & \multirow{3}{*}{$\begin{array}{c}\text { Colesterol hepático }(\mathrm{mg} / \mathrm{dL}) \\
\text { Final }\end{array}$} & \multicolumn{4}{|c|}{ Colesterol fecal (mg/dL) } \\
\hline & & \multicolumn{2}{|c|}{ Inicial } & \multicolumn{2}{|c|}{ Final } \\
\hline & & Média & Desvio-Padrão & Média & Desvio-Padrão \\
\hline Basal & 47,3 & 34,6 & $7,1^{e}$ & 42,3 & $8,6^{e}$ \\
\hline G1 & 160,7 & 96,0 & $2,6^{a}$ & 102,7 & $17,4^{d}$ \\
\hline $\mathrm{G} 2$ & 145,5 & 75,6 & $3,2^{c}$ & 159,2 & $6,6^{a}$ \\
\hline G3 & 134,8 & 86,8 & $10,7^{\mathbf{b}}$ & 140,2 & $8,9^{\mathbf{b}}$ \\
\hline G4 & 133,0 & 65,8 & $5,4^{d}$ & 120,8 & $10,7^{c}$ \\
\hline G5 & 79,5 & 81,0 & $7,3^{b c}$ & 147,2 & $21,0^{\mathrm{ab}}$ \\
\hline
\end{tabular}

Grupo basal: ratos que receberam ração comercial; G1: ratos que receberam ração hiperlipídica; G2: ratos que receberam ração hiperlipídica e $0,1 \mathrm{~mL}$ de suco de camu-camu; G3: ratos que receberam ração hiperlipídica e $1 \mathrm{~mL}$ de suco de camu-camu; G4: ratos que receberam ração hiperlipídica e $2 \mathrm{~mL}$ de suco de camu-camu; G5: ratos que receberam ração hiperlipídica e $2 \mathrm{mg}$ de quercetina. As médias são seguidas de desvio-padrão. Letras diferentes nas colunas indicam diferença significativa em nível de $5 \%$ de probabilidade, pelo Teste de Tukey.

Tabela 4. Consumo de ração (média e desvio-padrão) e massa corporal dos ratos durante o tratamento.

\begin{tabular}{|c|c|c|c|c|c|c|}
\hline \multirow{3}{*}{ Grupos } & \multirow{2}{*}{\multicolumn{2}{|c|}{ Consumo de ração (g) }} & \multicolumn{4}{|c|}{ Massa corporal (g) } \\
\hline & & & \multicolumn{2}{|c|}{ Inicial } & \multicolumn{2}{|c|}{ Final } \\
\hline & Média & Desvio-Padrão & Média & Desvio-Padrão & Média & Desvio-Padrão \\
\hline Basal & 263,8 & $24,5^{a}$ & 245,1 & $14,7^{\mathrm{a}}$ & 254,7 & $24,3^{\mathrm{a}}$ \\
\hline G1 & 211,8 & $13,9^{\mathbf{b}}$ & 232,9 & $28,1^{\mathrm{a}}$ & 239,5 & $32,5^{a}$ \\
\hline G2 & 214,5 & $22,9^{\mathbf{b}}$ & 254,0 & $14,8^{\mathrm{a}}$ & 232,5 & $13,4^{\mathrm{a}}$ \\
\hline G3 & 207,8 & $22,9^{\mathbf{b}}$ & 242,3 & $29,8^{a}$ & 238,5 & $25,9^{\mathrm{a}}$ \\
\hline G4 & 189,9 & $22,1^{\mathrm{c}}$ & 179,9 & $19,1^{\mathbf{b}}$ & 168,6 & $11,8^{\mathbf{b}}$ \\
\hline G5 & 173,1 & $27,7^{c}$ & 173,5 & $11,9^{\mathbf{b}}$ & 155,7 & $14,6^{\mathbf{b}}$ \\
\hline
\end{tabular}

Grupo basal: ratos que receberam ração comercial; G1: ratos que receberam ração hiperlipídica; G2: ratos que receberam ração hiperlipídica e $0,1 \mathrm{~mL}$ de suco de camu-camu; G3: ratos que receberam ração hiperlipídica e $1 \mathrm{~mL}$ de suco de camu-camu; G4: ratos que receberam ração hiperlipídica e $2 \mathrm{~mL}$ de suco de camu-camu; G5: ratos que receberam ração hiperlipídica e $2 \mathrm{mg}$ de quercetina. As médias são seguidas de desvio-padrão. Letras diferentes nas colunas indicam diferença significativa em nível de $5 \%$ de probabilidade, pelo Teste de Tukey. 


\section{A GRADECIMENTOS}

Ao Conselho Nacional de Desenvolvimento Científico e Tecnológico (Processo 553196/2005-7), Instituto Nacional de Pesquisas da Amazônia e Coordenação de Aperfeiçoamento de Pessoal de Nível Superior.

\section{COLABORADORES}

MC SCHWERTZ e LKO YUYAMA, contribuíram na concepção e desenho, análise e interpretação dos dados e redação. JRP MAIA. contribuiu nos modelos de indução da dislipidemia, na execução das atividades de biotério, análises bioquímicas e levantamento bibliográfico. RFS SOUSA contribuiu nas orientações das atividades pertinentes ao biotério, na execução das atividades de indução da dislipidemia e na coleta de material biológico. JPL AGUIAR contribuiu nas análises da composição química do camu-camu. ES LIMA contribuiu nas análises bioquímicas, interpretação e redação do artigo.

\section{REFERÊ N CIAS}

1. Sociedade Brasileira de Cardiologia. IV Diretriz Brasileira sobre dislipidemias e prevenção da aterosclerose do Departamento de Aterosclerose da Sociedade Brasileira de Cardiologia. Arq Bras de Cardiol. 2007; 88(Supl.1):2-19.

2. Costa RP, Menendez G, Bricarello LP, Elias MC, Ito M. Óleo de peixe, fitoesteróis, soja e antioxidantes: impactos nos lipídios e aterosclerose. Rev Soc Cardiol de São Paulo. 2000; 10(2):819-32.

3. Mcnamara DJ. Dietary cholesterol and atherosclerosis. Biochim Biophys Acta Mol Cell Biol Lipids. 2000; 1529(13):310-20.

4. Rodrigues HG, Diniz YS, Faine LA, Fernandes AAH, Novelli ELB. Suplementação nutricional com antioxidantes naturais: efeito da rutina na concentração de HDL-col. Rev Nutr. 2003; 16(3):315-20. doi: 101590/S1415-52732003000300009.

5. Flores WBC. Fruteiras diversas: a importância econômica do camu-camu. Toda Fruta. 1998; 3(1): 36-7.

6. Yuyama K, Aguiar JPL, Yuyama LKO. Camu-camu: um fruto fantástico como fonte de vitamina C. Acta Amaz. 2002; 32(1):169-74.
7. Yuyama LKO, Aguiar JPL, Yuyama K, Lopes TM, Fávaro DIT, Bergl PCB, et al. Teores de elementos minerais em algumas populações de camu-camu. Acta Amaz. 2003; 33(4):459-554.

8. Maeda RN, Andrade JS. Aproveitamento do camucamu (Myrciaria dubia) para produção de bebida alcoólica fermentada. Acta Amaz. 2003; 33(3): 489-98.

9. Manach C, Scalbert A, Morand C, Rémésy C, Jiménez L. "Polyphenols: food sources and bioavailability". Am J Clin Nutr. 2004; 79(5):727-47.

10. Lopes RM, Oliveira TT, Nagem TJ, Pinto AS. Flavonóides: farmacologia de flavonóides no controle hiperlipidêmico em animais experimentais. Biotecnologia Cien Desenvolv. 2000; 3(17):18-22.

11. Lin $B B$, Chen $\mathrm{HL}$, Huang $P C$. Effects on instant Pauchong Tea, Cathecin, and Caffeine os serum cholesterol and serum low-density-lipoprotein in mice. Nutr Rep Int. 1986; 34:821-9.

12. Hladovec J. The effect of antithrombotics in a new model of arterial thrombosis. Thromb Res. 1986; 41(5):665-70.

13. Kirk EA, Sutherland P, Wang SA, Shait A, Leboeuf $\mathrm{RC}$. Dietary isoflavones reduce plasma cholesterol and atherosclerosis in C57BL/6 mice but not LDL-receptor-deficient Mice. J Nutr. 1998; 128(6): 954-9.

14. Lin M, Anderson H, Flavin MT, Pai YS, MataGreenwood E, Pengsupap T, et al. In vitro anti-HIV activity of bioflavonoids isolated from rhus succedanea and garcania miltiflora. J Nat Prod. 1997; 60(9): 884-8.

15. Association of Official Analytical Chemists. Official methods of analysis. $12^{\text {th }}$ ed. Washington (DC): AOAC; 1995.

16. Instituto Adolfo Lutz. Normas analíticas, métodos químicos e físicos para análises de alimentos. São Paulo; 1975.

17. Asp NG, Johansson CG, Hallmer $H$, Siljestron $M$. Rapid enzymatic assay of insoluble dietary fiber. J Agric Food Chem. 1983; 31(3):43-53.

18. Lees DH, Francis FJ. Standartization of pigment analyses in cranberries. Hort Science. 1972; 7(1): 83-4.

19. Ranganna S. Analysis and quality control for fruit and vegetable products. New Delhi (India):Tata McGraw-Hill; 1986.

20. Mazalli MR, Saldanha T, Bragagnolo N. Determinação de colesterol em ovos: comparação entre um método enzimático e um método por cromatografia líquida de alta eficiência. Rev Inst Adolfo Lutz. 2003; 62(1):49-54.

21. Teixeira AS, Chaves LS, Yuyama K. Esterases no exame da estrutura populacional de camu-camu 
(Myrciaria dubia (Kunth) McVaugh-Myrtaceae). Acta Amaz. 2004; 34(1):89-96.

22. Justi KC, Visentainer JV, Souza NE, Matsushita M. Nutricional composition and vitamin C stability in stored camu-camu (Myrciaria dubia) pulp. Arch Latinoam Nutr. 2000; 50(4):405-8.

23. Maeda RN, Pantoja L, Yuyama LKO, Chaar JM. Determinação da formulação do néctar de camucamu (Myrciaria dúbia McVaugh). Ciênc Tecnol Aliment. 2006; 26(1):70-4.

24. Alves RE, Filgueiras HAC, Moura CFH, Araújo NCC, Almeida AS. Camu-camu (Myrciaria dubia McVaugh): a rich natural source of vitamin C. Proc Interamer Soc Trop Hort. 2002; 46:11-3.

25. Nijveldt RJ, van Nood E, van Hoorn ECD, Boelens PG, Norren KK, Leeuwen PAML. Flavonoids: a review of probable mechanisms of action and potential applications. Am J Clin Nutr. 2001; 74(4): 418-25.

26. Pierpoint WS. Flavonoids in the human diet. Prog Clin Biol Res. 1986; 213: 125-40

27. Kohrle J, Spank M, Cody V, Irmascher K, Prucher $H$, Hesch RD. Characteristics of a new synthetic thyrinine antagonist. Ann Endocrinol. 1986; 47:58-65.

28. Pinto AS, Oliveira TT, Nagem TJ, Gomes SM, Costa NMB, Oliveira MGA. Ação de flavonóides sobre os níveis de lipídios em ratos tratados com triton e seus efeitos antioxidantes. Rev Esc Farm Odontol Alfenas. 1999; 21:21-8.

29. Tall AR. Metabolic fate of chylomicon phospholipids and apoproteins in the rat. J Clin Invest. 1979; 64(4): 977-89.

30. Chajeck T, Eisenberg S. Very low density lipoprotein. Metabolism of phospholipids, cholesterol and apolipoprotein $C$ in the isolated perfused rat heart. J Clin Invest. 1978; 61(6):1654-65.

31. Scalbert A, Willianson G. Dietary intake and bioavailability of polyphenols. J Nutr. 2000; 130(8): 2073S-85S.

32. Aprikian O, Busserolles J, Manach C, Mazur A, Morand C, Davicco MJ, et al. Lyophilised apple counteracts the development of hypercholesterolemia, oxidative stress, and renal dysfunction in obese Zucker rats. J Nutr. 2002; 132(7):1969-76.

33. Li F, Li W, Fu W, Zhang Q, Koike K. Pancreatic LipaseInhibiting Triterpenoid Saponins from Fruits of Acanthopanax senticosus. Chem Pharm Bull. 2007; 55(7):1087-9.

Recebido em: 21/6/2010

Versão final reapresentada em: 10/8/2011

Aprovado em: 20/9/2011 